\title{
Peningkatan Rasa Percaya Diri Siswa Tunagrahita Melalui Pembelajaran Terintegrasi Semiotik Dengan Media Buku Pop Up
}

\author{
Mu'jizatin Fadiana*1, Citra Dewi Rosalina ${ }^{2}$ \\ 1,2 Universitas PGRI Ronggolawe Tuban \\ ${ }^{1}$ Program Studi Pendidikan Matematika, Fakultas Keguruan dan Ilmu Pendidikan \\ ${ }^{2}$ Program Studi PGPAUD, Fakultas Keguruan dan Ilmu Pendidikan \\ *e-mail: mujizatin000@gmail.com ${ }^{1}$ citradewi.ra@gmail.com²
}

\begin{abstract}
This service program is motivated by the lack of confidence in communicating retarded students in SLB C Autis Negeri Tuban. This is caused by the lack of mastery and understanding of vocabulary. Therefore, by using a semiotic integrated learning design with pop up book media it is hoped that it will increase the mental retardation students' confidence in communicating with others. This dedication program is carried out in the form of classroom action research involving 10 mild retarded students $(C)$ and 5 moderate retarded students (C1). The team applies semiotic integrated learning with pop-up book media for six meetings. The results of this program indicate that there is an increase in confidence in mild and moderate retarded students at SLB C Autis Negeri Tuban in terms of self-show by boldly appearing in front of the class, telling stories, and answering questions, besides that there is a process of interaction and communication in learning activities between educators with students and fellow friends when the performance activities take place.
\end{abstract}

Keywords: Semiotic Learning, Pop Up Books, Confidence, mentally retarded

\begin{abstract}
Abstrak
Program pengabdian ini dilatarbelakangi oleh rendahnya rasa percaya diri dalam berkomunikasi siswa tunagrahita di SLB C Autis Negeri Tuban. Hal ini disebabkan oleh minimnya penguasaan dan pemahaman kosakata. Oleh karena itu, dengan menggunakan desain pembelajaran terintegrasi semiotik dengan media buku pop up diharapkan akan meningkatkan rasa percaya diri siswa tunagrahita dalam berkomunikasi dengan orang lain. Program pengabdian ini dilaksanakan dalam bentuk tindakan kelas yang melibatkan 10 siswa tunagrahita ringan (C) dan 5 siswa tunagrahita sedang (C1). Tim menerapkan pembelajaran terintegrasi semiotik dengan media buku pop up selama enam kali pertemuan. Hasil program ini menunjukkan bahwa adanya peningkatan rasa percaya diri pada siswa tunagrahita ringan dan sedang di SLB C Autis Negeri Tuban dalam hal unjuk diri dengan berani tampil di depan kelas, bercerita, dan menjawab pertanyaan, selain itu terjadi proses interaksi dan komunikasi dalam kegiatan pembelajaran antara pendidik dengan peserta didik dan sesama teman saat kegiatan unjuk diri berlangsung.
\end{abstract}

Kata kunci: Pembelajaran Semiotik, Media Buku Pop Up, Rasa Percaya Diri, Tunagrahita

\section{PENDAHULUAN}

Pendidikan adalah hak semua warga negara tanpa memandang status sosial, ras, etnis, suku, dan bangsa, termasuk anak yang menyandang kecacatan. Anak-anak yang menyandang kecacatan bukanlah produk gagal yang harus didiskriminasikan bahkan dikucilkan dalam masyarakat. Mereka adalah makhluk Tuhan dan Tuhan tidak pernah menciptakan produk gagal. Dibalik kecacatannya, mereka menyimpan banyak kelebihan dan potensi. Dengan kesempatan yang sama dalam memperoleh akses pendidikan, mereka akan mengoptimalkan semua potensi yang dimiliki sehingga mereka bisa percaya diri hidup di tengah-tengah masyarakat.

Dalam dunia pendidikan ditemukan anak-anak yang memiliki kecerdasan secara signifikan berada di bawah rata-rata pada umumnya dan disertai dengan hambatan dalam tingkah laku penyesuaian diri dan termanifestasi selama periode perkembangan. Di Indonesia anak-anak tersebut dikenal dengan istilah Tunagrahita (PP No72/91) dan istilah-istilah lainnya adalah: mentally retarded, mental retardation, intellectually disabled, mentally handicapped. Ketunagrahitaan tidak hanya berdasarkan satu aspek saja, misalnya hanya segi kecerdasan saja 
yang rendah tetapi harus melihat hal-hal lain seperti adanya ketidak mampuan dalam tingkah laku penyesuaian dan masa terjadinya.

Karakterisktik keterbatasan yang dialami anak tunagrahita, antara lain; 1) keterbatasan intelegensi, bahwa anak tunagrahita mengalami kesulitan dalam memahami materi yang diajarkan guru dikarenakan mengalami permasalahan dibidang akademiknya, 2) keterbatasan sosial, bahwa anak tunagrahita kategori sedang mengalami permasalahan dalam berinteraksi di lingkungannya ataupun dalam kehidupan bermasyarakat sehingga anak cenderung bergaul dengan anak yang berada jauh dibawah usianya, dan 3) keterbatasan fungsi fungsi mental lainnya, bahwa tunagrahita mengalami permasalahan dalam membedakan baik buruk, anak belum mampu bertindak sesuai dengan aturan yang berlaku di lingkungannya ataupun di dalam masyarakat (Somantri, 2007).

SLB C Autis Negeri Tuban adalah salah satu sekolah yang menampung anak tunagrahita di Kabupaten Tuban Jawa Timur. Jumlah seluruh peserta didik sebanyak 120 siswa dengan kebutuhan khusus yang dilayani meliputi C (tunagrahita ringan), C1 (tunagrahita sedang) dan Q (Autis). Dari keseluruhan jumlah peserta didik yang ada di SLB Negeri Tuban terdapat 102 siswa tunagrahita pada klasifikasi tunagrahita ringan dan tunagrahita sedang. Mitra dari program pengabdian masyarakat ini adalah siswa tunagrahita ringan dan tungrahita sedang di SLB C Autis Negeri Tuban Kelas I sebanyak 15 siswa. Anak tunagrahita ringan mempunyai kemampuan untuk dididik dengan rentang IQ 50-75, sedangkan anak tunagrahita sedang mempunyai kemampuan untuk dilatih dengan rentang IQ 25-50.

Hasil observasi selama pembelajaran di kelas didapatkan gambaran bahwa anak tunagrahita memiliki kesulitan dalam berbahasa dalam menyampaikan apa yang dipikirkan dan dirasakan. Sehingga mereka sulit untuk beradaptasi dan bertingkah laku. Dalam belajar di kelas, anak tunagrahita perlu dibimbing dan bergantung pada guru. Guru harus menyampaikan maksud dan tujuan dengan bahasa yang mudah dipahami anak dengan perlahan dikarenakan anak sulit memahami pembicaraan karena kurangnya kosakata mereka. Di sisi lain, terdapat anak tunagrahita yang suka berbicara dan banyak mengucapkan kosakata namun kosakata yang diucapkan tidak bisa dimengerti oleh orang lain. Mereka seperti membeo. Anak tunagrahita juga sulit untuk berkonsentrasi dalam belajar di kelas. Rentang waktu konsentrasi untuk memusatkan perhatiannya pada suatu hal sangat pendek, sehingga guru harus mempunyai cara khusus agar anak fokus dan memahami apa yang disampaikan oleh guru seperti memperlihatkan bentuk atau visualisasi dari suatu kata atau mencari kosakata lain yang mudah diterima oleh anak. Salah satu dari akibat dari kurangnya daya konsentrasi pada anak tunagrahita adalah mereka seringkali keliru menyebutkan antara huruf "b" dan huruf "d", antara huruf "c" dan "e". Selain itu, mereka juga mudah lupa dengan apa yang baru saja diucapkan.

Selama ini guru menggunakan model pembelajaran langsung dengan strategi pembelajaran yang diindividualisasikan. Strategi individualisasi artinya bahwa siswa belajar bersama-sama dalam satu kelas tetapi kedalaman dan keluasan materi, pendekatan/metode maupun teknik berbeda-beda disesuaikan dengan kemampuan dan kebutuhan setiap siswa. Guru lebih banyak mencatat di papan tulis serta pembimbingan secara individu pada siswa. Guru kurang memvisualkan maksud pembicaraannya, seperti dengan menggunakan gerakan tubuh (gestur), gambar, benda konkret ataupun cara lain agar siswa mengerti maksud pembicaraan guru. Media pembelajaran yang digunakan di sekolah hanyalah buku pedoman untuk guru sehingga anak menulis apa yang ditulis guru di papan tulis, sehingga anak hanya mengetahui kosakatanya saja tetapi tidak memahami bentuk konkret maupun gambar visualnya. Setelah menulis di papan tulis, guru berkeliling untuk menanyakan pada siswa tentang kosakata yang kurang dimengerti siswa. Ketika ditanya oleh guru, siswa tidak merespon pertanyaan guru dan hanya diam sambil tersenyum. Kurangnya rasa percaya diri pada anak tunagrahita membuat mereka malu bertanya dan berbicara langsung pada guru maupun orang asing dikarenakan kurangnya kosakata yang mereka miliki. Dalam hal mengenal kosakata baru anak tunagrahita harus melihat langsung bentuk konkret maupun bentuk visual dari kosakata tersebut agar anak mudah memahami dan berkonsentrasi.

Berdasarkan pada permasalahan yang dihadapi mitra, maka perlu dikembangkan pembelajaran terintegrasi semiotik dengan media buku pop up. Pembelajaran terintegrasi 
semiotik adalah pembelajaran yang menggunakan perspektif semiotik. Semiotik adalah sebuah teori yang mempelajari tentang tanda, berfungsinya tanda dan makna yang dihasilkan oleh tanda. Pembelajaran yang terintegrasi semiotik adalah pembelajaran yang memanfaatkan semua tanda yang muncul baik dari siswa maupun dari guru. Semiotik meliputi tanda visual, verbal, tactile dan olfactory (semua tanda atau sinyal yang bisa diakses dan diterima oleh seluruh indera). Proses berpikir tidak hanya mediated by, tetapi juga located in body, artifacts, dan signs (Radford, 2006). Terdapat beberapa komponen semiotik yang bisa diamati proses belajar mengajar yaitu gestur, kata-kata yang diucapkan dan simbol tertulis (Fadiana, Amin \& Lukito, 2018 ). Gestur atau gerak tubuh yang menyertai siswa maupun guru selama pembelajaran. Gestur (gerak tubuh) mempunyai peran dalam pembelajaran, yaitu untuk membantu komunikasi ide-ide baik bagi guru maupun siswa (Fadiana, 2016). Anak yang tahap berpikirnya pada tahap operasional konkret banyak dimediasi oleh gestur, baik gestur menunjuk maupun gestur representasional (Fadiana, Amin \& Lukito, 2018 ). Bila anak operasional konkret dalam dalam proses berpikirnya banyak dimediasi oleh gestur, maka anak tunagrahita dimungkinkan akan terbantu dengan pembelajaran yang melibatkan gerak tubuh (gestur). Karena tahap perkembangan kognitif anak tunagrahita belum mencapai tahap operasional konkret.

Pembelajaran yang terintegrasi semiotik diharapkan dapat membantu anak tunagrahita dalam memahami kosakata, sehingga dengan bertambahnya kosakata yang dipahami semakin meningkatkan rasa percaya diri anak tunagrahita dalam bersosialisasi dalam lingkungannya dan berkomunikasi dengan orang lain. Komunikasi senantiasa membutuhkan bahasa, baik bahasa verbal maupun bahasa non verbal. Salah satu jenis bahasa nonverbal adalah bahasa tubuh yang bisa dilihat dari gerak tubuh (gestur). Komunikasi verbal yang dilakukan seharihari akan lebih mudah dipahami oleh orang lain bila disertai dengan komunikasi nonverbal. Dalam pembelajaran di kelas, guru dan siswa berkomunikasi dengan bahasa verbal disertai nonverbal. Guru sering menghasilkan gestur ketika mengajar (Alibali \& Nathan, 2007) dan siswa juga sering menghasilkan gestur ketika berbicara atau berdiskusi dengan teman (Bieda \& Nathan, 2009).

Selain gestur, pembelajaran yang terintegrasi semiotik juga mengoptimalkan penggunaan simbol-simbol. Simbol yang bisa digunakan pada saat pembelajaran dapat berupa gambar visual. Guru dapat menggunakan gambar visual untuk menjelaskan maksud sebuah kosakata pada peserta didik tunagrahita. Guru tidak hanya menuliskan kosakata di papan tulis. Dengan melihat gambar visual, peserta didik tunagrahita diharapkan dapat memahami maksud kosakata yang sedang dipelajari dan rentang waktu konsentrasi mereka lebih panjang.

Salah satu jenis gambar visual yang bisa digunakan adalah buku pop-up. Buku pop-up dapat dijadikan sebagai media pembelajaran dalam melatih, menarik dan membantu anak dalam kebahasaan (Rosalina \& Nugrahani, 2018). Namun, tidak hanya bergambar saja melainkan gambar yang memiliki imajinasi yang tinggi. Buku pop-up merupakan buku yang di dalamnya jika dibuka maka muncul gambar atau tulisan yang timbul (tiga dimensi). Buku pop-up ini bisa dikreasikan menjadi beberapa fungsi, salah satunya yaitu buku pop-up yang digunakan untuk anak yaitu bisa berbentuk cerita atau disampaikan dalam bentuk kartu pop-up huruf alphabet yang dijadikan satu menjadi satu buku secara utuh yang memuat huruf alphabet A sampai dengan huruf Z. Media buku pop-up merupakan salah satu alternatif media pembelajaran anak yang dengan potensi yang dimilikinya dapat menarik perhatian anak (Rosalina \& Nugrahani, 2018). Dengan menggunakan media buku pop up diharapkan dapat meningkatkan imajinasi dan antusias anak tunagrahita terhadap materi yang diajarkan, sehingga rentang daya konsentrasi mereka untuk mengikuti pelajaran bisa lebih lama.

\section{METODE}

Program pengabdian ini dilaksanakan di SLB C Autis Negeri Tuban, yang beralamat Jalan Dr. Wahidin Sudirohusodo Nomor 867 Kelurahan Sidorejo Kecamatan Tuban Kabupaten Tuban, dengan sasaran siswa tunagrahita ringan (C) dan siswa tunagrahita sedang (C1). Adapun tahapan pengabdian yang akan dilaksanakan adalah sebagai berikut: 
1. Tim (Dosen) melakukan diskusi dengan guru yang mengajar mitra tentang materi pelajaran, waktu dan setting kegiatan pengabdian yang akan dilaksanakan.

2. Tim (Dosen dan mahasiswa) mengembangkan buku pop up sebagai media pembelajaran terintegrasi semiotik. Pengembangan buku pop ini disesuaikan dengan kebutuhan sekolah mitra berdasarkan hasil diskusi antara tim pengusul dengan guru yang mengajar mitra.

3. Tim (Dosen) merancang pembelajaran terintegrasi semiotik (mulai dari perencanaan, proses pemilihan materi, dan penggunaan media buku pop up dan sebagainya). Perancangan pembelajaran dikaji berdasarkan teori semiotik yang pernah diteliti oleh tim pengusul dan disesuaikan dengan kebutuhan sekolah mitra berdasarkan hasil diskusi antara tim pengusul dengan guru yang mengajar mitra.

4. Tim (Dosen dan Mahasiswa) menerapkan pembelajaran terintegrasi semiotik dengan media buku pop up untuk beberapa kali pertemuan sampai tujuan yang diharapkan bisa terwujud. Guru yang mengajar mitra bertindak sebagai shadow teacher (ST) selama pembelajaran dilaksanakan. Kegiatan pembelajaran didokumentasikan berupa video pembelajaran. Video pembelajaran ini nantinya akan menjadi referensi bagi sekolah mitra untuk mengembangkan dan menerapkan pembelajaran terintegrasi semiotik setelah kegiatan pengabdian ini selesai.

5. Tim (dosen dan mahasiswa) melakukan observasi dan wawancara kepada mitra untuk mendapatkan data tentang rasa percaya diri dalam berkomunikasi. Pengukuran rasa percaya diri dalam berkomunikasi menggunakan angket. Dari hasil observasi dan wawancara kemudian dianalisis secara deskriptif kuantitatif.

\section{HASIL DAN PEMBAHASAN}

Pelaksanaan kegiatan Pengabdian Kemitraan Masayarakat (PKM) dilakukan pada bulan Februari-Maret 2020 melalui beberapa tahapan. Adapun hasil dan pembahasan dari masingmasing tahapan adalah sebagai berikut:

\subsection{Tahap Perencanaan}

Pada tahap perencanaan, tim yang terdiri atas dosen dan mahasiswa melakukan observasi dan diskusi dengan guru yang mengajar mitra, yaitu siswa Kelas I SLB C Autis Negeri Tuban yang menyandang tunagrahita ringan dan tunagrahita sedang. Program pengabdian ini dilaksanakan dalam bentuk tindakan kelas yang melibatkan 10 siswa tunagrahita ringan (C) dan 5 siswa tunagrahita sedang (C1). Tim melakukan observasi pembelajaran di kelas juga wawancara dengan guru kelas dan kepala sekolah. Siswa Kelas I SLB C Autis Negeri Tuban mempunyai tingkat ketunagrahitaan yang berbeda-beda. Mereka memiliki kekurangan dan kelemahan yang berbedabeda, sehingga guru menggunakan pendekatan pembelajaran secara individual, yaitu mendampingi dan mengarahkan siswa secara individual. Guru kurang memberi kesempatan pada siswa untuk unjuk diri di depan kelas untuk menumbuhkan rasa percaya diri.

Siswa cenderung asyik dengan dunianya sendiri, mengoceh sendiri, memainkan mainan yang dibawa, mengganggu temannya dan diam saja. Sehingga saat proses pembelajaran berlangsung siswa tidak fokus terhadap materi yang disampaikan oleh guru. Namun masih ada dua orang siswa yang fokus terhadap penjelasan guru dan aktif menjawab pertanyaan guru. Dua orang siswa tersebut menyandang tunagrahita ringan.

Selain pendekatan pembelajaran guru yang kurang menarik, media pembelajaran yang digunakan guru juga terbatas. Guru hanya menggunakan media white board. Pada saat mengenalkan lambang bilangan, guru hanya menunjukan lambang bilangan dengan menuliskannya pada white board. Siswa tidak diberikan kesempatan untuk unjuk kepercayaan diri dalam mengenal lambang bilangan. Selain itu, siswa juga kurang termotivasi mengikuti pembelajaran. 


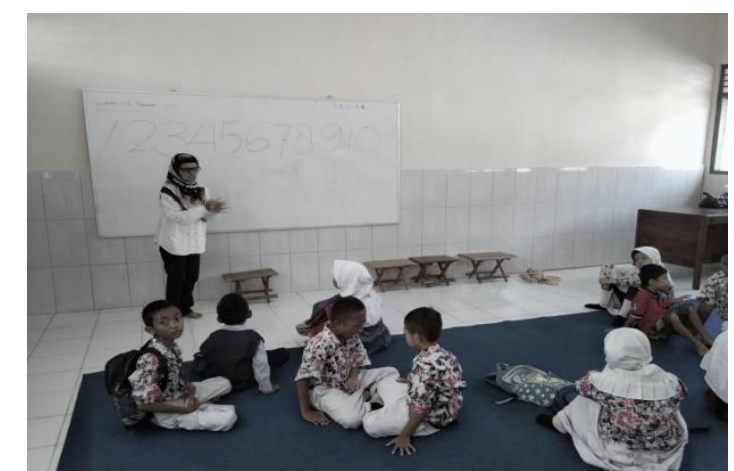

Gambar 1. Guru mengenalkan lambang bilangan dengan menggunakan white board

Setelah observasi awal di kelas, tim melakukan koordinasi dengan kepala sekolah dan guru yang mengajar mitra tentang materi pelajaran, waktu dan setting kegiatan pengabdian yang akan dilaksanakan. Kepala sekolah dan guru menerima dengan baik dan merasa senang dengan adanya program pengabdian masyarakat ini. Guru menjelaskan tentang keterbatasan media pembelajaran yang dimiliki oleh sekolah. Selain itu, guru juga merasa terbatas waktu dan tenaga untuk mengembangkan media pembelajaran, sehingga dalam melaksanakan pembelajaran guru tidak pernah menggunakan media pembelajaran. Adapun materi pelajaran yang digunakan untuk kegitan pengabdian ini adalah materi pengenalan lambang bilangan, pengenalan pola garis, pengenalan bangun ruang, penjumlahan bilangan 1-10 dan kegiatan di siang hari dan malam hari.

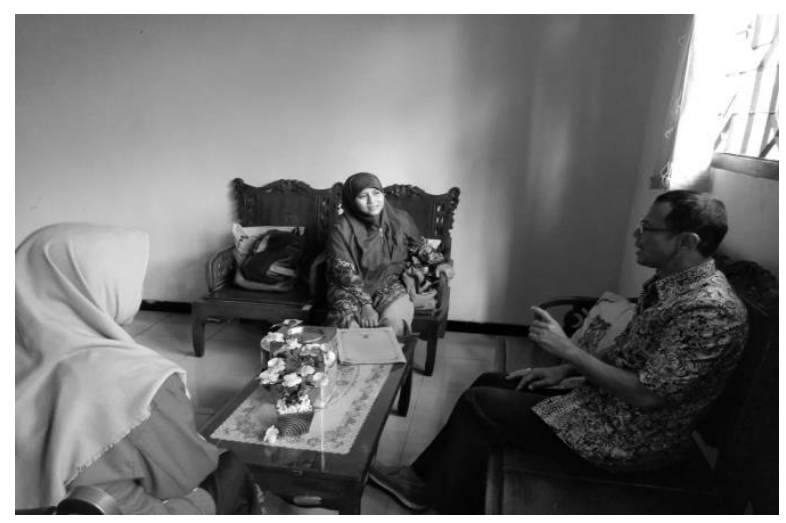

Gambar 2. Tim melakukan koordinasi dengan kepala sekolah

Berdasarkan hasil observasi di kelas dan koordinasi dengan guru dan kepala sekolah, tim pengabdi yang terdiri atas dosen dan mahasiswa mengembangkan buku pop up sebagai media pembelajaran juga merancang pembelajaran berbasis semiotik. Pembelajaran berbasis semiotik adalah pembelajaran yang menggunakan semua tanda yang dimengerti oleh siswa, baik berupa gestur (gerak tangan), mimik wajah, simbol, tulisan maupun kata-kata yang dimengerti oleh siswa tunagrahita. Perancangan pembelajaran dikaji berdasarkan teori semiotik yang pernah diteliti oleh tim pengusul dan disesuaikan dengan kebutuhan sekolah mitra berdasarkan hasil diskusi antara tim pengusul dengan guru yang mengajar mitra. 


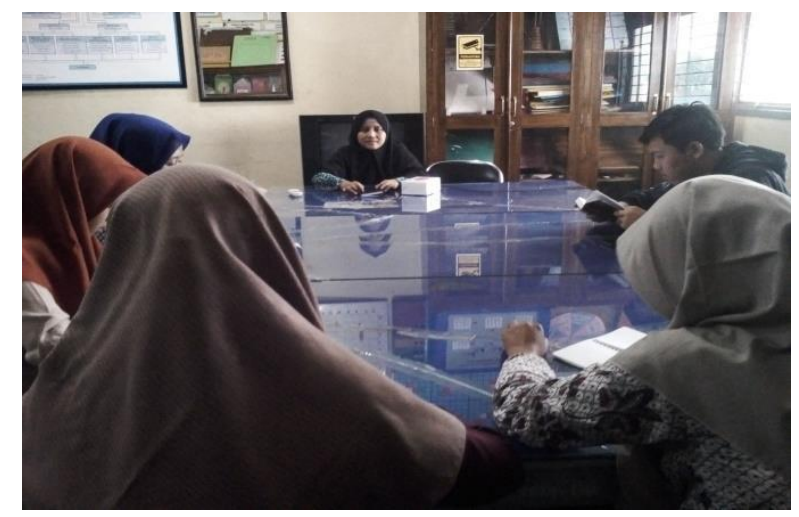

Gambar 3. Tim berdiskusi untuk merancang pelaksanaan pengabdian

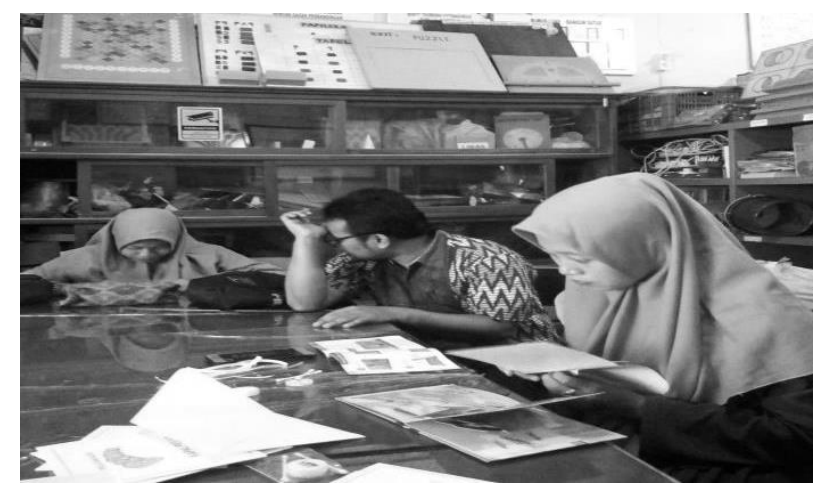

Gambar 4. Tim mengembangkan buku pop-up

\subsection{Tahap Pelaksanaan}

Tim pengabdi melaksanakan pembelajaran yang terintegrasi semiotik dengan mengguanakan buku pop up yang telah dirancang dan dikembangkan. Model pembelajaran menggunakan model pembelajaran tematik. Hal ini dikarenakan di SLB C Autis Negeri Tuban Kelas I menggunakan pembelajaran tematik. Pengabdi tidak mengubah model pembelajaran yang digunakan, namun pengabdi menggabungkan antara model pembelajaran tematik dengan strategi semiotik dan menggunakan media buku pop up. Tujuan utama pelaksanaan kegiatan pembelajaran ini adalah menumbuhkan rasa percaya diri siswa tunagrahita dalam berkomunikasi. Rasa percaya diri akan muncul ketika siswa tunagrahita sering diberi kesempatan untuk unjuk diri di depan kelas dan juga sering diajak untuk berkomunikasi yang bisa mereka pahami.

Dalam melaksanakan pembelajaran yang terintegrasi semiotik, tim pengabdi menyampaikan materi pelajaran dengan menggunakan semua tanda (sign) yang dimengerti oleh siswa tunagrahita. Semua tanda (sign) meliputi tanda verbal dan non verbal. Tanda verbal meliputi konten bahasa dan penggunaan bahasa secara lisan, sedangkan tanda non verbal meliputi gestur yang berupa gerak tangan dan gerak tubuh, ekspresi wajah dan tanda tertulis berupa gambar.

Pelaksanaan pembelajaran terintegrasi semiotik juga menggunakan media buku pop up. Buku pop-up yang berbentuk tiga dimensi yang sangat menarik perhatian siswa tunagrahita, dapat menumbuhkan rasa ingin tahu dan motivasi untuk mengikuti pembelajaran. Media buku pop-up merangsang siswa tunagrahita untuk bertanya dan bercerita sesuai dengan imajinasinya. Hal ini dikarenakan desain, warna, ilustrasi gambar juga ilustrasi cerita dari buku pop-up yang digunakan bisa mengembangkan daya imajinasi dan rasa ingin tahu siswa tunagrahita. Salah satu cara untuk melatih siswa tunagrahita percaya diri dalam berkomunikasi adalah dengan memberinya kesempatan untuk unjuk diri di depan kelas baik secara individu maupun bersama- 
sama dengan temannya. Ketika tampil di depan kelas, siswa diminta untuk mengutarakan pendapatnya, menceritakan kembali jalan cerita yang terdapat pada buku pop-up dan menjawab pertanyaan dari tim pengabdi.

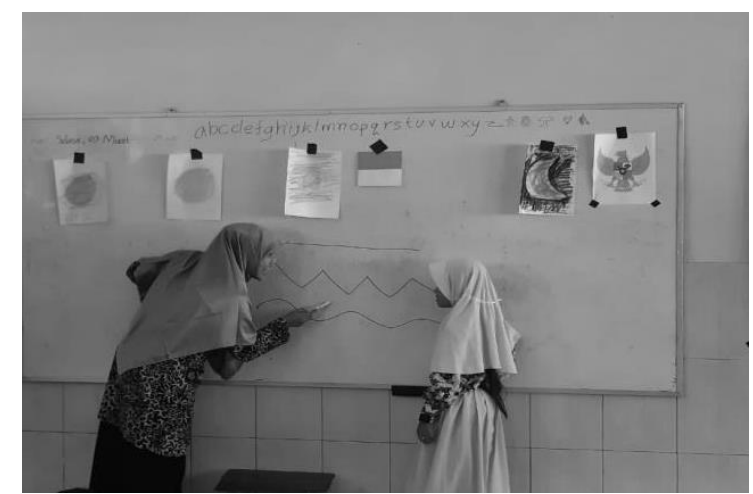

Gambar 5. Tim melakukan pembelajaran terintegrasi semiotik

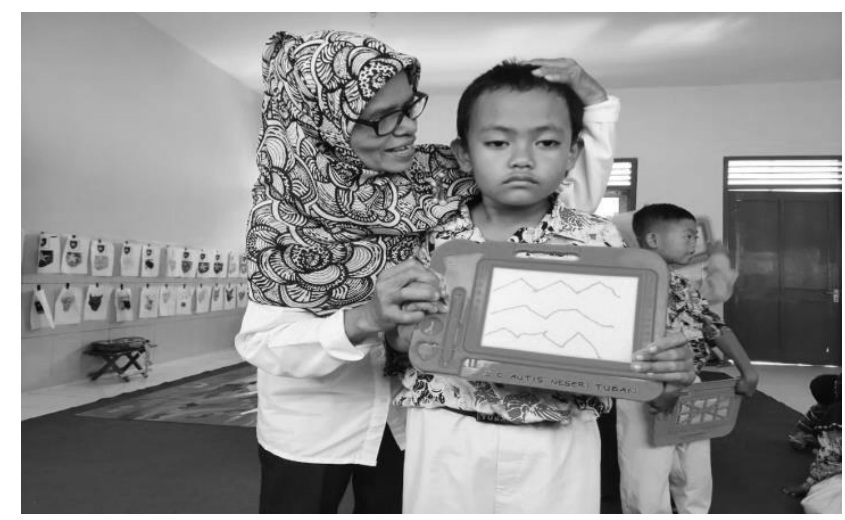

Gambar 6. Guru mitra bertindak sebagai shadow teacher berikut

Adapun pengukuran tingkat percaya diri dalam berkomunikasi menggunakan rubrik

Tabel 1. Rubrik Penilaian Percaya Diri

\begin{tabular}{|c|c|c|c|}
\hline Aspek & Indikator & Deskripsi & Skor \\
\hline \multirow[t]{3}{*}{ Percaya Diri } & Percaya Diri & $\begin{array}{l}\text { a. Berani tampil di depan kelas tanpa } \\
\text { didampingi guru } \\
\text { b. Berani bercerita } \\
\text { c. Berani menjawab pertanyaan dengan } \\
\text { baik } \\
\text { d. Berani bertanya }\end{array}$ & 3 \\
\hline & $\begin{array}{c}\text { Kurang Percaya } \\
\text { Diri }\end{array}$ & $\begin{array}{l}\text { a. Berani tampil di depan kelas } \\
\text { didampingi guru } \\
\text { b. Bercerita dengan malu-malu } \\
\text { c. Malu dalam menjawab pertanyaan } \\
\text { d. Malu untuk bertanya }\end{array}$ & 2 \\
\hline & Tidak Percaya Diri & $\begin{array}{l}\text { a. Tidak Berani tampil di depan kelas } \\
\text { b. Tidak mau bercerita } \\
\text { c. Tidak mau menjawab pertanyaan } \\
\text { d. Tidak berani bertanya }\end{array}$ & 1 \\
\hline
\end{tabular}




\subsection{Tahap Evaluasi}

Program pengabdian masyarakat dilaksanakan selama 9 kali pertemuan pembelajaran yang terbagi dalam tiga siklus. Setiap siklus terdiri atas 3 pertemuan. Siklus I tim mengajarkan materi tentang mengenal lambang bilangan 1-10, siklus II materi tentang aktivitas siang hari dan malam hari sedangkan siklus III materi tentang mengenal bentuk benda. Setiap selesai satu siklus dilakukan pengukuran tingkat kepercayaan diri dalam berkomunikasi.

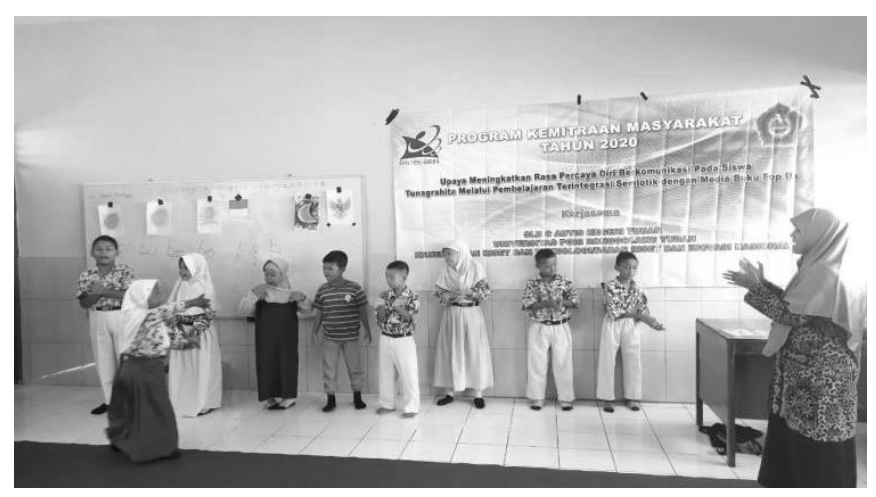

Gambar 7. Siswa unjuk diri di depan kelas

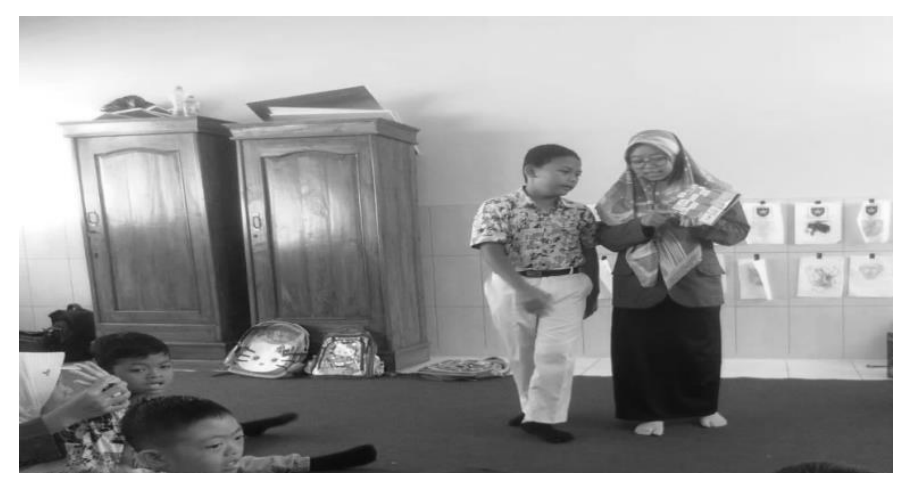

Gambar 8. Siswa bercerita di depan kelas

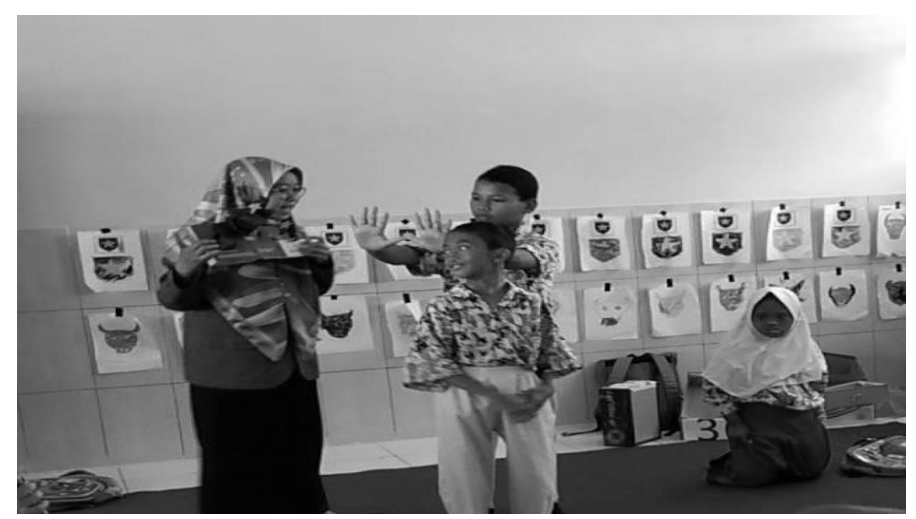

Gambar 9. Siswa berkomunikasi dengan tim di depan kelas 


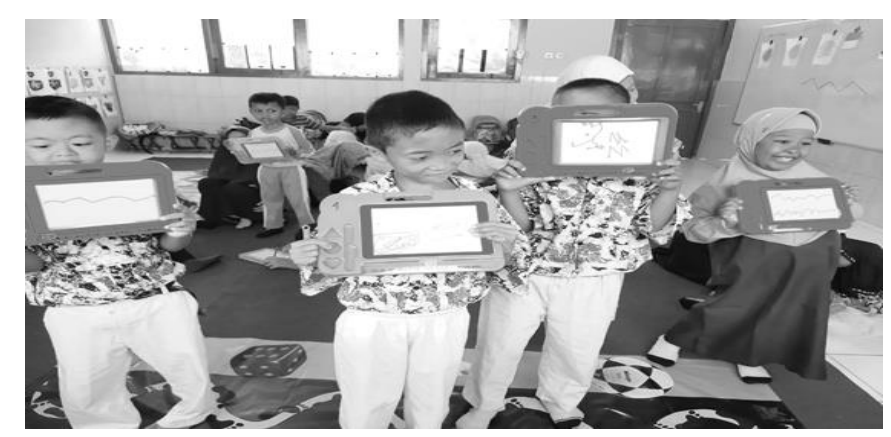

Gambar 10. Siswa berani menunjukkan hasil tugas

Adapun hasil pengukuran tingkat percaya diri dalam berkomunikasi selama siklus I, siklus II dan siklus III adalah sebagai berikut:

Tabel 2. Hasil Pengukuran Tingkat Kepercayaan Diri Siswa Tunagrahita Kelas I SLB C Autis Negeri Tuban pada Siklus I, Siklus II dan Siklus III

\begin{tabular}{ccccc}
\hline \multirow{2}{*}{ No } & Indikator & \multicolumn{3}{c}{ Prosentase } \\
\cline { 3 - 5 } & & Siklus I & Siklus II & Siklus III \\
\hline 1 & Percaya Diri & $22,5 \%$ & $63 \%$ & $84,6 \%$ \\
\hline 2 & Kurang Percaya Diri & $44 \%$ & $20,3 \%$ & $12,5 \%$ \\
\hline 3 & Tidak Percaya Diri & $33,5 \%$ & $16,7 \%$ & $2,9 \%$ \\
\hline
\end{tabular}

Berdasarkan Tabel 2, bisa dilihat bahwa terjadi peningkatan rasa percaya diri siswa tunagrahita selama pembelajaran terintegrasi semiotik dengan menggunakan media buku pop-up. Peningkatan ini disebabkan karena pembelajaran berpusat pada peserta didik dengan memberikan kesempatan kepada peserta didik untuk unjuk diri dan tim pengabdi berperan sebagai fasilitator. Pembelajaran yang berpusat pada peserta didik meningkatkan keaktifan serta memberikan kesempatan pada peserta didik untuk menggali potensinya, meskipun mereka butuh waktu yang lebih lama bila dibandingkan dengan peserta didik normal. Dengan memberikan kesempatan pada siswa tunagrahita untuk berpartisipasi aktif dalam pembelajaran baik dengan cara unjuk diri, berdiskusi, tampil di depan kelas atau menyempaikan pendapat melatih anak terbiasa berbicara di depan umum serta dapat meningkatkan kepercayaan diri. Keterlibatan anak secara langsung dan berdiskusi dengan bertukar cerita pada anak, secara tidak langsung menumbuhkan rasa percaya diri pada anak (Hendra, 2006).

Kegiatan pembelajaran yang menyenangkan dapat meningkatkan antusias dan motivasi siswa tunagrahita dalam mengikuti pembelajaran, didukung dengan media pembelajaran yang menarik membuat anak lebih mudah memahami materi yang disampaikan. Pemilihan media pembelajaran yang menarik sangat penting karena media yang digunakan harus lebih menarik perhatian siswa tunagrahita sehingga rentang waktu konsentrasi siswa tunagrahita lebih panjang dan tidak merasa bosan dengan kegiatan tersebut. Dalam hal ini media yang dimaksud adalah buku pop-up. Dengan media buku pop-up siswa tunagrahita dapat memahami materi dengan mudah, karena media buku pop-up sangat menarik dan mampu menampilkan gambar dalam bentuk tiga dimensi. Sehingga siswa tunagrahita dapat belajar dengan media yang menyenangkan serta mudah dipahami. Tidak hanya itu, penggunaan media pembelajaran berupa buku yang menarik juga dapat menumbuhkan daya inovasi dan kreativitas siswa (Nuraini \& Subiyanto, 2018). Dengan adanya penyajian dan pemberian kegiatan pembelajaran menggunakan berbagai media yang bervariasi dapat melatih kepercayaan diri anak untuk melakukan setiap kegiatan baru tanpa adanya ketakutan dalam diri untuk mencoba (Timothy, 2012). Percaya diri pada anak terjadi melalui berbagai proses yaitu dengan unjuk diri, kegiatan unjuk diri yang dilakukan dalam proses pembelajaran adalah berani tampil di depan kelas, bercerita, dan menjawab pertanyaan. Selain itu, melatih anak berani unjuk diri dapat dilakukan dengan memanggil anak bersama dengan anak-anak yang lain, untuk tampil di depan kelas (Iskarima, 2009). Berbicara dengan keras di kelas dapat membantu anak lebih berani dalam mengungkapkan pendapatnya. Sehingga 
untuk melatih kepercayaan diri anak dapat dilakukan dengan dibiasakan untuk unjuk diri, serta membiarkan anak bereksplorasi terhadap lingkungannya untuk memuaskan rasa ingin tahu anak tunagrahita sehingga dapat berkembang.

\section{KESIMPULAN}

Berdasarkan hasil program pengabdian masyarakat yang telah dilakukan, maka dapat disimpulkan bahwa dengan pembelajaran tematik yang terintegrasi semiotik dengan media buku pop up dapat meningkatkan rasa percaya diri siswa tunagrahita Kelas I SLB C Autis Negeri Tuban. Peningkatan kepercayaan diri siswa tunagrahita dapat dilihat dari adanya peningkatan pada hasil observasi pada pelaksanaan pengabdian masyarakat selama siklus I, siklus II, siklus III. Pada pelaksanaan tindakan, kepercayaan diri peserta didik mengalami peningkatan melalui pembelajaran semiotik yang menggunakan semua tanda baik verbal maupun non verbal dalam berkomunikasi. Unjuk diri dengan media buku pop-up berpengaruh terhadap hasil siklus I, II dan III serta mempunyai dampak terhadap rasa percaya diri peserta didik. Percaya diri pada anak terjadi melalui berbagai proses yaitu dengan unjuk diri, kegiatan unjuk diri yang dilakukan dalam proses pembelajaran adalah berani tampil di depan kelas, bercerita, dan menjawab pertanyaan.

\section{UCAPAN TERIMA KASIH}

Penulis mengucapkan terima kasih kepada Direktorat Riset dan Pengabdian Masyarakat Deputi Bidang Penguatan Riset dan Pengembangan Kementerian Riset dan Teknologi/Badan Riset dan Inovasi Nasional yang telah mendanai program pengabdian ini melalui Kontrak Pelaksanaan Program Pengabdian Kepada Masyarakat Nomor 105/SP2H/PPM/DRPM/2020 dan LPM Universitas PGRI Ronggolawe Tuban

\section{DAFTAR PUSTAKA}

Somantri, S. (2007). Psikologi Anak Luar Biasa. Bandung: PT. Rineka Aditama

Radford, L. (2006). Algebraic Thinking and The Generalization of Patterns: A Semiotic Perspective. Alatorre, S., Cortina, J.L., Sáiz, M., and Méndez, A.(Eds) (2006). Proceedings of the 28 annual meeting of the North American Chapter of the International Group for the Psychology of Mathematics Education. Mérida, México: Universidad PedagógicaNacional. Vol. 1. 1-21

Fadiana, M., Amin, S. M., \& Lukito, A. (2018). Profil Generalisasi Berdasarkan Perspektif Semiotik Siswa Operasional Konkret Dan Operasional Formal. Jurnal Ilmiah Pendidikan Matematika. Vol. 3(2). 99-106

Fadiana, M. (2016). Peran Gestur Dalam Pembelajaran Matematika. Prosiding Seminar Nasional Masif II Tahun 2016. Semarang : FMIPATI Universitas PGRI Semarang

Alibali, M. W., \& Nathan, M. J. (2007). Teachers' gestures as a means of scaffolding students' understanding: Evidence from an early algebra lesson. In R. Goldman, R. Pea, B. Barron, \& S. J. Derry (Eds.), Video research in the learning sciences,349-365, Mahwah, NJ: Erlbaum

Bieda, K. N., \& Nathan, M. J. (2009). Representational disfluency in algebra: Evidence from student gestures and speech. ZDM-The International Journal on Mathematics Education. Vol. 41. 637-650

Rosalina,C.D., \& Nugrahani, R. (2018). Pengembangan Media Buku Pop-Up Untuk Pembelajaran Mengenal Huruf Alphabet Anak Usia Dini. Prosiding Seminar Nasional Hasil Penelitian Dan Pengabdian Kepada Masyarakat III Universitas PGRI Ronggolawe Tuban. Tuban: LPPM Universitas PGRI Ronggolawe Tuban

Hendra, S. (2006). Kiat Membina Anak Agar Senang Berkawan. Jakarta: PT. Elex Media Komputindo.

Nuraini, P \& Subiyanto. (2018). Media Pembelajaran Srapbook pada HIMPAUDI Magelang Utara. DINAMISIA-Jurnal Pengabdian Kepada Masyarakat. Vol 2 (1). 38-41 
Timothy, W. (2012). 7 Cara Meningkatkan Rasa Percaya Diri Anak. Diakses dari http://www.pendidikankarakter.com/wp-content/uploads/7-CaraMeningkatkan-RasaPercaya-Diri-Anak.pdf pada tanggal 27 September 2019

Iskarima, R. (2009). Super Confident Child: Tips Agar Anak Pemberani dan Percaya Diri. Yogyakarta: Impremium. 